ARTICLE

https://doi.org/10.1038/s41467-019-11134-8

\title{
Divergent synthesis of chiral cyclic azides via asymmetric cycloaddition reactions of vinyl azides
}

Nuligonda Thirupathi ${ }^{1}$, Fang Wei ${ }^{1}$, Chen-Ho Tung ${ }^{1} \&$ Zhenghu Xu ${ }^{1,2}$

Vinyl azides, bearing conjugated azide and alkene functional groups, have been recognized as versatile building blocks in organic synthesis. In general vinyl azides act as 3-atom (CCN) synthons through the fast release of molecular nitrogen and have been extensively utilized in the construction of structurally diverse $\mathrm{N}$-heterocycles. Keeping the azide moiety intact in organic transformations to synthesis chiral azides is an important but challenging task. Herein, we report an enantioselective copper(II)/BOX-catalyzed cycloaddition of vinyl azides, generating diverse chiral cyclic azides. $\alpha$-Aryl substituted vinyl azides react with unsaturated keto esters through an inverse-electron-demand hetero-Diels-Alder reaction to afford chiral azido dihydropyrans with excellent enatioselectivities. In contrast, cyclohexenyl azides undergo a diastereo- and enantio-selective Diels-Alder reaction giving important azido octahydronaphthalenes with three continuous stereogenic centers. Notable features of these reactions include a very broad scope, mild reaction conditions and $100 \%$ atom economy.

\footnotetext{
${ }^{1}$ Key Lab of Colloid and Interface Chemistry of Ministry of Education, School of Chemistry and Chemical Engineering, Shandong University, No. 27 South Shanda Road, 250100 Jinan, Shandong, China. ${ }^{2}$ State Key Laboratory of Organometallic Chemistry, Shanghai Institute of Organic Chemistry, Chinese Academy of Sciences, 200032 Shanghai, PR China. Correspondence and requests for materials should be addressed to Z.X. (email: xuzh@sdu.edu.cn)
} 
O rganic azides are energy-rich, flexible intermediates and have attracted significant interest in recent decades ${ }^{1,2}$. Among them, a special subclass, chiral azides, are extensively distributed in many bioactive molecules ${ }^{3,4}$, and are valuable chiral synthons in organic synthesis. They can participate in diverse transformations, such as cycloaddition, reduction, and aza-Wittig reactions to give chiral nitrogen-containing products. Chiral azides have been utilized as key intermediates in the total synthesis of many natural products, such as callipeltosides A and $\mathrm{B}^{5}$, and pharmaceuticals such as the antibiotic chloramphenicol ${ }^{6}$. Moreover, application of chiral azides in copper(I)catalyzed Huisgen cycloaddition with alkynes has become a powerful click chemistry tool ${ }^{7-10}$, widely used in chemical biology $^{7}$, drug discovery ${ }^{8}$, and also synthesis of chiral materials ${ }^{9}$. Current methods to synthesize chiral azides are mainly stereospecific transformations from chiral starting materials ${ }^{11-13}$; development of catalytic asymmetric approaches is important and has attracted great attention in recent years ${ }^{14}$. Several methods involving asymmetric nucleophilic or electrophilic azidation of prochiral compounds, with a key enantioselective $\mathrm{C}-\mathrm{N}_{3}$ bond formation, have been developed ${ }^{15-23}$, but it is always difficult to control enantiofacial selectivity when handling the very small azido group. Catalytic asymmetric transformation of organic azides into chiral azides is an attractive alternative, which does not involve $\mathrm{C}-\mathrm{N}_{3}$ bond construction ${ }^{24-28}$. Such transformations are comparatively less common, because keeping the energy-rich reactive azido group intact in asymmetric transformations is a challenge.

Vinyl azides bearing azide and alkene functional groups conjugated together, could be easily obtained by the reaction of silver-catalzyed hydroazidation of terminal alkynes ${ }^{29}$, and have been recognized as versatile building blocks in organic synthesis ${ }^{2,30-32}$. Generally, vinyl azides undergo a fast release of two nitrogens to generate vinyl nitrene or strained $2 \mathrm{H}$ aziridine intermediates, and subsequent cycloaddition or radical addition reactions lead to structurally diverse $\mathrm{N}$-heterocycles $^{33-40}$ (Fig. 1a). Vinyl azides can also react with electrophiles to form iminium ions, or undergo Schmidt-type rearrangements driven by loss of a dinitrogen unit to afford functionalized amides ${ }^{41}$. In this general denitrogenation reactivity mode, vinyl azides act as an important three-atom synthon in the construction of complex $N$-heterocyclic skeletons and have been extensively studied in recent years. Although keeping the conjugated azide moiety intact in organic transformations is a challenge ${ }^{42}$, such reactions can afford valuable organic azides which are highly desirable. For instance, in 2017, López et al. developed a copper(I)-catalyzed [3+2]cycloaddition of vinyl azides, with unsaturated carbene

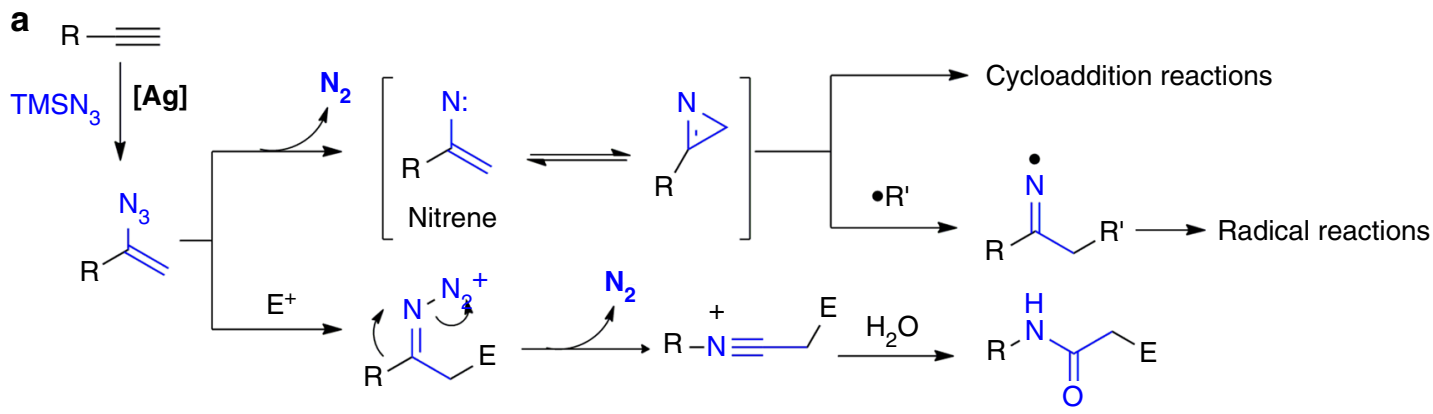

b

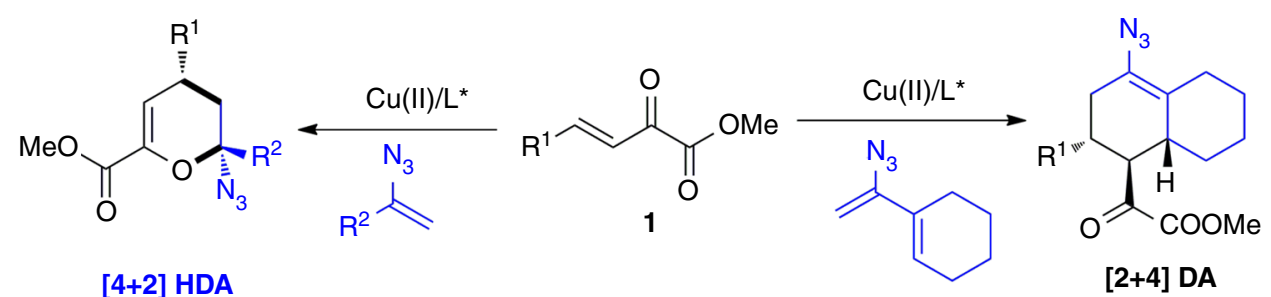

Substrate-guided enantioselective [4+2] HDA and [2+4] DA reactions

Synthesis of cyclic chiral azides

$100 \%$ atom economy

c<smiles>CC1=C[C@H]2C(C(C)C)CC=C(C)[C@H]2CC1</smiles>

Cadinene<smiles>C=C(C)C1CCC2(C)CCC(=O)C(C)=C2C1</smiles>

Cyperone

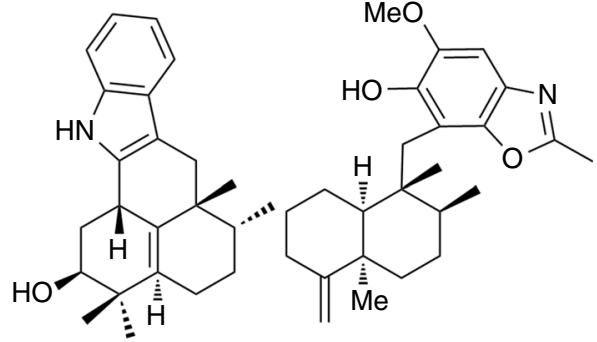

Pentacyclindol
5-epi-Nakijinol E

Fig. 1 Reactivities of vinyl azides. a General reactivity of vinyl azides as CCN synthon driven by the release of $\mathrm{N}_{2}$. $\mathbf{b}$ Cycloaddition reactivity of vinyl azides with azide retention (this work). c Selected important natural sesquiterpenoids with decalin motif 
precursors, to produce azidocyclopentenes ${ }^{43}$. However, this reaction requires $50 \mathrm{~mol} \%$ of catalyst loading and only racemic reactions were reported. Consequently, the development of an efficient catalytic asymmetric cycloaddition reaction of vinyl azides to produce chiral azides is important. We report here the copper(II)-catalyzed asymmetric [4+2]-cycloaddition of vinyl azides with unsaturated ketone esters (1) to build chiral cyclic azides (Fig. 1b). More importantly, structurally diverse cyclic azides were obtained through a substrate reactivityguided inverse-electron-demand hetero-Diels-Alder or Diels-Alder reactions. The Diels-Alder reaction produces a very important decalin motif, which is an omnipresent structural unit in a wide range of natural products, with various significant biological activities (Fig. 1c) ${ }^{44-50}$. Many important natural sesquiterpenoids and diterpenoids are isoprenoid decalins, for example, cadinene and cyperone are components of important essential oils from plants, and the natural indole sesquiterpenes pentacyclindole ${ }^{47}$ and 5-epi-nakijinol $\mathrm{E}^{48}$ have important antiproliferative and cytotoxic activities. Generally, such decalin scaffolds are built by a long linear stepwise construction of a chiral triene structure, followed by an intramolecular DA reaction ${ }^{45,50}$. The intermolecular catalytic asymmetric Diels-Alder reaction not reported to date is a more effective synthetic route to access this scaffold.

\section{Results}

Optimization of HDA reaction. To avoid formation of nitrenetype intermediates, we took advantage of the nucleophilic character of the $\mathrm{C}=\mathrm{C}$ bond in vinyl azides, which enables it to react at low temperatures with highly electron-deficient unsaturated ketone esters (1) through an inverse-electron-demand heteroDiels-Alder (HDA) reaction. We reasoned that when a chiral Lewis acid catalyst is applied to activate the unsaturated ketone ester (1) through chelation with the two carbonyl groups, chiral azides might be generated by a catalytic asymmetric reaction.

A vinyl azide (2a) and the ketone ester (1a) were selected as model substrates to test this reactivity in the presence of various Lewis acids (Table 1). The reaction proceeds smoothly in the presence of several metal Lewis acids, such as $\mathrm{Sc}(\mathrm{OTf})_{3}, \mathrm{InCl}_{3}$, and $\mathrm{Cu}(\mathrm{OTf})_{2}$, giving however the target azide-containing product (3a) in moderate-to-good yield with moderate diastereoselectivity (entries 1-3). The endo-adduct (3a) is the major product under these conditions. In view of the wide application of $\mathrm{Cu}(\mathrm{II}) /$ bisoxazoline (BOX) catalysts in asymmetric catalysis, we further tried to realize the catalytic asymmetric reaction to produce chiral cyclic azides. Details are provided in Supplementary Table 1. A screening of various bisoxazoline ligands (entries 4-9) revealed that $\mathrm{Ph}-\mathrm{BOX}(\mathbf{L 1})$ or $t$-Bu-BOX (L3) gave very high enantioselectivity of $94 \%$ and $98 \%$ ee, respectively. Other ligands

Table 1 Optimization of reaction conditions ${ }^{a}$

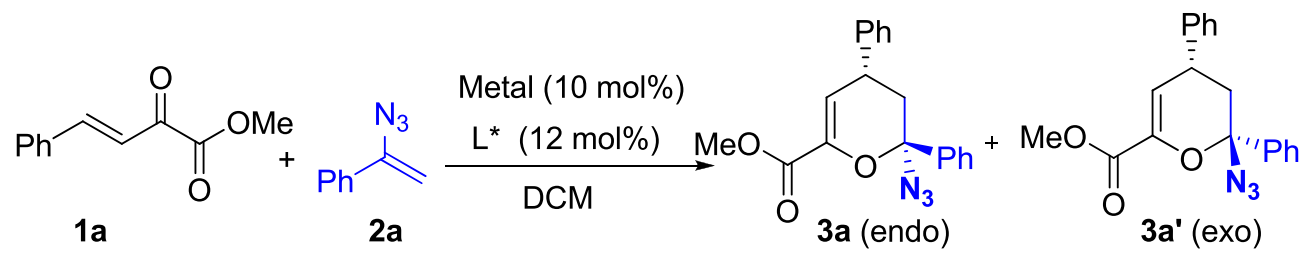<smiles>[R]C1COC(C([R])([R])C2=NC([R])CO2)=N1</smiles>
L1, R = Ph, R' = R" = Me
L2, $R=B n, R^{\prime}=R^{\prime \prime}=M e$
L5, $\mathrm{R}={ }^{\mathrm{i}} \mathrm{Pr}, \mathrm{R}^{\prime}=\mathrm{R}^{\prime \prime}=\mathrm{Bn}$
3, $\mathrm{R}={ }^{t} \mathrm{Bu}, \mathrm{R}^{\prime}=\mathrm{R}^{\prime \prime}=\mathrm{Me}$
L9, $\mathrm{R}=\mathrm{Ph}, \mathrm{R}^{\prime}=\mathrm{Me}, \mathrm{R}^{\prime \prime}={ }^{-}{ }^{\mathrm{t}} \mathrm{BuC}_{6} \mathrm{H}_{4} \mathrm{CH}_{2}$
L4, R = Ph, R' = R" = 4- ${ }^{t} \mathrm{BuC}_{6} \mathrm{H}_{4} \mathrm{CH}_{2}$

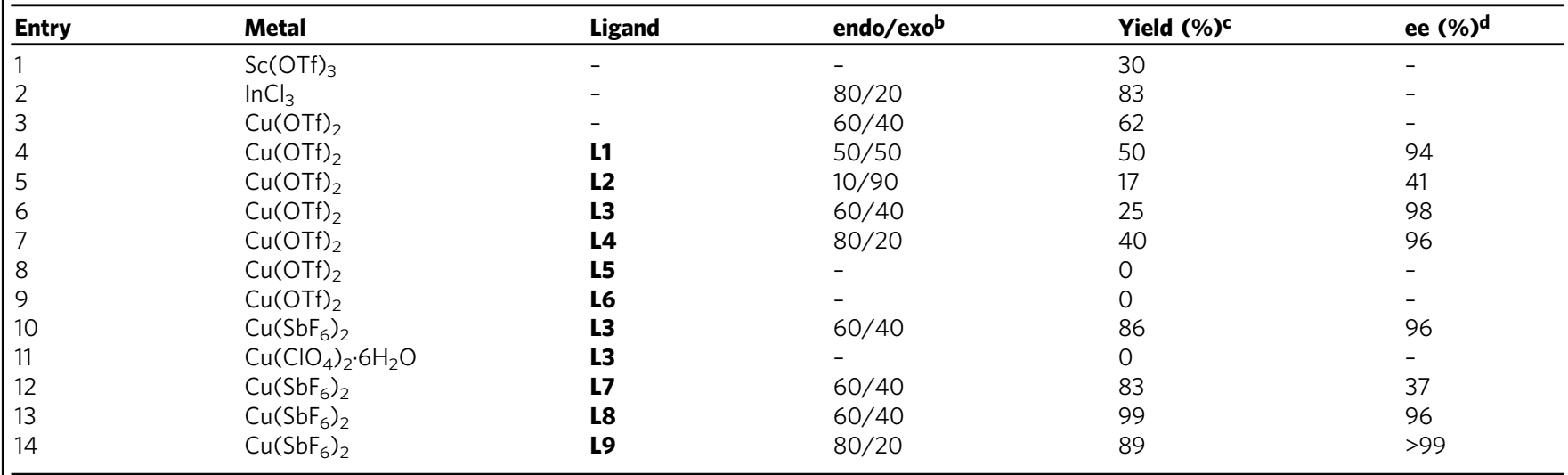

aReaction conditions: a mixture of $\mathbf{1 a}(0.2 \mathrm{mmol}), \mathbf{2 a}(0.24 \mathrm{mmol})$, metal catalyst $(10 \mathrm{~mol} \%)$, and ligand $(12 \mathrm{~mol} \%)$, solvent $(2 \mathrm{~mL}), 30^{\circ} \mathrm{C}$

betermined by crude ${ }^{1} \mathrm{H}$ NMR analysis

${ }^{\mathrm{c} C o m b i n e d}$ isolated yield

dDetermined by HPLC using a chiral stationary phase 
Table 2 Scope of $\mathrm{Cu}$ (II)-catalyzed hetero-Diels-Alder reactions ${ }^{\mathrm{a}}$

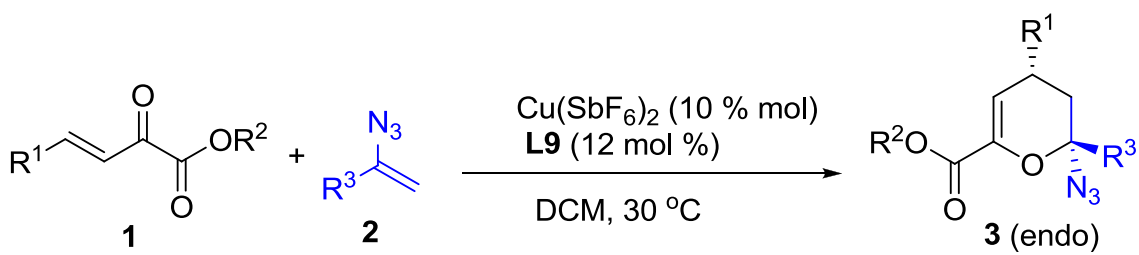

\begin{tabular}{|c|c|c|c|c|c|c|}
\hline Entry & $1\left(R^{1}, R^{2}\right)$ & $2\left(R^{3}\right)$ & 3 & endo/exo & Yield (\%) & ee (\%)c \\
\hline 1 & 1a $(\mathrm{Ph}, \mathrm{Me})$ & $\mathbf{2 a}(\mathrm{Ph})$ & $3 \mathbf{a}$ & $80 / 20$ & 89 & $>99$ \\
\hline 2 & $1 \mathbf{a}$ & $\mathbf{2 b}\left(4-\mathrm{ClC}_{6} \mathrm{H}_{4}\right)$ & $\mathbf{3 b}$ & $80 / 20$ & 82 & 97 \\
\hline 3 & 1a & 2c $\left(4-\mathrm{FC}_{6} \mathrm{H}_{4}\right)$ & $3 c$ & $78 / 22$ & 84 & 96 \\
\hline 4 & 1a & 2d $\left(4-\mathrm{BrC}_{6} \mathrm{H}_{4}\right)$ & 3d & $75 / 25$ & 85 & 99 \\
\hline 5 & 1a & $2 \mathbf{e}\left(4-\mathrm{MeOC}_{6} \mathrm{H}_{4}\right)$ & $3 e$ & $60 / 40$ & 94 & 72 \\
\hline 6 & $\mathbf{1 a}$ & $2 f\left(4-\mathrm{MeC}_{6} \mathrm{H}_{4}\right)$ & $3 f$ & $90 / 10$ & 74 & 95 \\
\hline 7 & $1 \mathbf{a}$ & $2 \mathrm{~g}\left(4-\mathrm{C}^{-} \mathrm{BuC}_{6} \mathrm{H}_{4}\right)$ & $3 g$ & $93 / 7$ & 66 & 98 \\
\hline 8 & $\mathbf{1 a}$ & $\mathbf{2 h}\left(4-\mathrm{PhC}_{6} \mathrm{H}_{4}\right)$ & $3 \mathrm{~h}$ & $74 / 26$ & 80 & 97 \\
\hline 9 & $\mathbf{1 a}$ & $2 \mathbf{i}\left(3-\mathrm{ClC}_{6} \mathrm{H}_{4}\right)$ & $3 i$ & $84 / 16$ & 74 & 98 \\
\hline 10 & 1a & $\mathbf{2 j}\left(3-\mathrm{MeC}_{6} \mathrm{H}_{4}\right)$ & $\mathbf{3 j}$ & $91 / 9$ & 54 & 97.5 \\
\hline 11 & 1a & 2k (2-naphthyl) & 3k & $78 / 22$ & 88 & 97 \\
\hline 12 & $\mathbf{1 a}$ & 21 (3-thienyl) & 31 & $72 / 28$ & 81 & 90 \\
\hline 13 & $\mathbf{1 b}(\mathrm{Ph}, \mathrm{Et})$ & $\mathbf{2 a}(\mathrm{Ph})$ & $3 \mathbf{m}$ & $86 / 14$ & 82 & 99.5 \\
\hline 14 & 1c $(\mathrm{Ph}, \mathrm{iPr})$ & $\mathbf{2 a}(\mathrm{Ph})$ & $3 \mathbf{n}$ & $88 / 12$ & 80 & 98 \\
\hline 15 & 1d $\left(4-\mathrm{MeC}_{6} \mathrm{H}_{4}, \mathrm{Bn}\right)$ & $\mathbf{2 a}(\mathrm{Ph})$ & 30 & $91 / 9$ & 58 & 98 \\
\hline 16 & 1e $\left(4-\mathrm{ClC}_{6} \mathrm{H}_{4}, \mathrm{Me}\right)$ & $2 a(P h)$ & $3 p$ & $90 / 10$ & 78 & 97 \\
\hline 17 & If $\left(4-\mathrm{BrC}_{6} \mathrm{H}_{4}, \mathrm{Me}\right)$ & $2 a(P h)$ & 39 & $90 / 10$ & 75 & 97 \\
\hline 18 & $\mathbf{1 g}\left(4-\mathrm{FC}_{6} \mathrm{H}_{4}, \mathrm{Me}\right)$ & $\mathbf{2 a}(\mathrm{Ph})$ & $3 r$ & $84 / 16$ & 86 & 97 \\
\hline 19 & 1h $\left(4-\mathrm{MeC}_{6} \mathrm{H}_{4}, \mathrm{Me}\right)$ & $\mathbf{2 a}(\mathrm{Ph})$ & 3s & $89 / 11$ & 94 & 99 \\
\hline 20 & ii $\left(4-\mathrm{MeOC}_{6} \mathrm{H}_{4}, \mathrm{Me}\right)$ & $2 \mathbf{a}(\mathrm{Ph})$ & 3t & $93 / 7$ & 58 & 98 \\
\hline 21 & $\mathbf{j j}\left(3-\mathrm{BrC}_{6} \mathrm{H}_{4}, \mathrm{Me}\right)$ & $\mathbf{2 a}(\mathrm{Ph})$ & 3u & $90 / 10$ & 67 & 96.7 \\
\hline 22 & ik (2-naphthyl, Me) & $2 a(P h)$ & $3 v$ & $90 / 10$ & 81 & $>99$ \\
\hline 23 & 11 (3-thienyl, Me) & $\mathbf{2 a}(\mathrm{Ph})$ & $3 w$ & $84 / 16$ & 86 & 97 \\
\hline
\end{tabular}

Table 3 Optimization of the Cu(II)-catalyzed DA reactions ${ }^{\mathrm{a}}$<smiles>COC(=O)C(=O)/C=C/c1ccccc1</smiles>

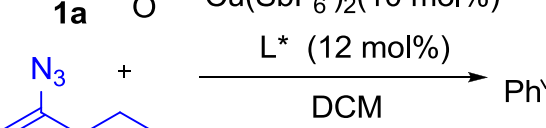<smiles>COC(=O)C1C2CCCCC2=C(N)C[C@@H](c2ccccc2)C1C(=O)OC</smiles>

$4 a$<smiles>[R]C([R])(C1=N[C@@H](C(C)(C)C)CO1)C1=N[C@@H](C(C)(C)C)CO1</smiles>

L10, R' = R" = - $\mathrm{CH}_{2} \mathrm{CH}_{2}$

L11, R' = R" = - $\left(\mathrm{CH}_{2}\right)_{5-}$

L12, R' = R" = - $\left(\mathrm{CH}_{2}\right)_{4}^{-}$

\begin{tabular}{|c|c|c|c|c|}
\hline Entry & Ligand & $T\left({ }^{\circ} \mathrm{C}\right)$ & Yield (\%)b & ee $(\%)^{c}$ \\
\hline 1 & L9 & 30 & 84 & 21 \\
\hline 2 & L8 & 30 & 64 & 73 \\
\hline 3 & L3 & 30 & 75 & 80 \\
\hline 5 & L10 & -20 & 84 & 87 \\
\hline 6 & L11 & -20 & 81 & 84 \\
\hline 7 & L12 & -20 & 80 & 93 \\
\hline
\end{tabular}

aReaction conditions: a mixture of $\mathbf{1 a}(0.2 \mathrm{mmol}), \mathbf{2} \mathbf{m}(0.24 \mathrm{mmol}), \mathrm{Cu}\left(\mathrm{SbF}_{6}\right)_{2}(10 \mathrm{~mol} \%)$, and ligand $(12 \mathrm{~mol} \%)$ 
Table 4 Substrate scope of $\mathrm{Cu}(\mathrm{II})$-catalyzed DA reactions ${ }^{\mathrm{a}}$<smiles>[R]C=CC(=O)C(=O)O[R]</smiles><smiles>CCOC(=O)C1[C@H]2CCCCC2=C(N)C[C@H]1c1ccccc1</smiles><smiles>CCCOC(=O)C(=O)C1C2CCCCC2=C(N)C[C@H]1c1ccc(C)cc1</smiles><smiles>COC(=O)[C@@H]1[C@@H]2CCCCC2=C(N)C[C@@H]1c1ccc(C)cc1</smiles>

4b, $88 \%{ }^{b}(89 \% \text { ee })^{c}$

4c, $82 \%(85 \%$ ee $)$

4d, $84 \%(91 \%$ ee $)$<smiles>COC(=O)C1[C@H]2CCCCC2=C(N)C[C@H]1c1ccsc1</smiles><smiles>COC(=O)[C@H]1[C@@H](c2cccc(Cl)c2)CC(N)=C2CCCC[C@]21C(=O)O</smiles><smiles>COC(=O)[C@@H]1[C@@H]2CCCCC2=C(N)C[C@H]1c1ccc(Br)cc1</smiles>
$4 \mathbf{e}, 79 \%(86 \%$ ee $)$<smiles>COC(=O)C1[C@@H]2CCCC2=C(N)C[C@H]1c1ccccc1</smiles>

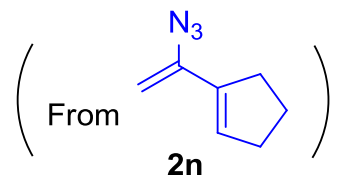

$4 \mathrm{~h}, 87 \%(88 \% \text { ee })^{\mathrm{e}}$

aReaction conditions: $\mathbf{1}(0.2 \mathrm{mmol}), \mathbf{2 m}$ or $\mathbf{2 n}(0.24 \mathrm{mmol}), \mathrm{Cu}\left(\mathrm{SbF}_{6}\right)_{2}(10 \mathrm{~mol} \%)$, and $\mathbf{L} \mathbf{1 2}(12 \mathrm{~mol} \%)$ at $-20^{\circ} \mathrm{C}$

blsolated yield

CDetermined by HPLC using a chiral stationary phase

dAt $-10^{\circ} \mathrm{C}$

eAt $-30^{\circ} \mathrm{C}$

such as Bn-BOX (L2), $i$ Pr-BOX (L5), and $i \operatorname{PrPyBOX~(L6)~all~gave~}$ inferior results. Further screening of various copper salts using ligand $\mathrm{L} 3$ revealed that $\mathrm{Cu}\left(\mathrm{SbF}_{6}\right)_{2}$ gave an $86 \%$ yield and $96 \%$ ee, albeit with a low 60/40 diastereomeric ratio (dr) (entry 10). Recently, the Tang group have developed a successful sidearm modification strategy to elaborate the bisoxazoline ligands by introducing a pendant group at the bridging carbon ${ }^{51-55}$. We synthesized the sidearm-modified BOX ligands L8 and L9 and the $\mathrm{Ph}-\mathrm{BOX}$ ligand bearing one pendant $4-t-\mathrm{BuC}_{6} \mathrm{H}_{4}$ group (L9) gave the best results, affording the desired azide product in $89 \%$ yield with $>99 \%$ ee and $80 / 20 \mathrm{dr}$ (entry 14).

Substrate scope of HDA reaction. After establishing the optimal conditions for the asymmetric cycloaddition reaction, the scope of substrates was further investigated. First, the reactivities of various vinyl azides were tested. As shown in Table 2, aromatic vinyl azides bearing various electron-withdrawing or electrondonating functional groups at the phenyl ring are well tolerated and produced the corresponding cyclic azides in good-toexcellent yields with high enantioselectivities $(72-99 \%$ ee, entries 1-10). Strong electron-donating 4-methoxyl-substituted azides (2e) appear to be too reactive in this inverse-electrondemand HDA and give a lower ee of $72 \%$ (entry 5). The vinyl azides (2k) bearing a 2-naphthyl group and $2 \mathbf{l}$ containing a thienyl group also reacted smoothly under the standard conditions, giving the corresponding azides $\mathbf{3 k}$ and $3 \mathbf{l}$ with $97 \%$ and $90 \%$ ee, respectively (entries 11, 12). However, aliphatic vinyl azides were found to be averse to this transformation. Then the scope of unsaturated ketoesters was also explored (Table 2). Various unsaturated ketoesters with both electron-withdrawing and electron-donating aromatic substituents at the $\gamma$-position all react smoothly with vinyl azide (2a), giving cyclic azides $(\mathbf{3 m}-\mathbf{3 w})$ in good yields with excellent enantioselectivities ( $>97 \%$ ee, entries 
a

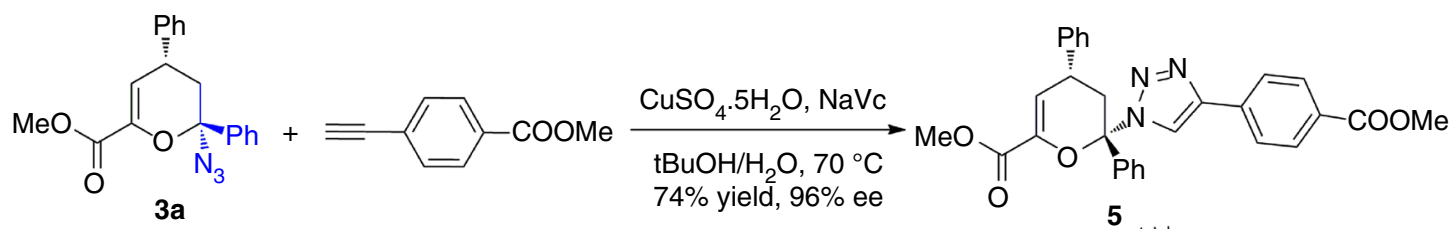
3a

b<smiles>COC(=O)C1=CC(c2ccccc2)C=C(c2ccccc2)O1</smiles>

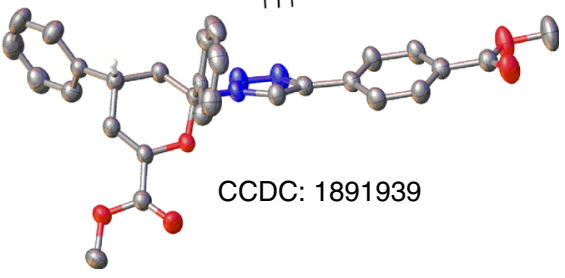

C<smiles>C#Cc1ccc(C(=O)OC)cc1</smiles>

d

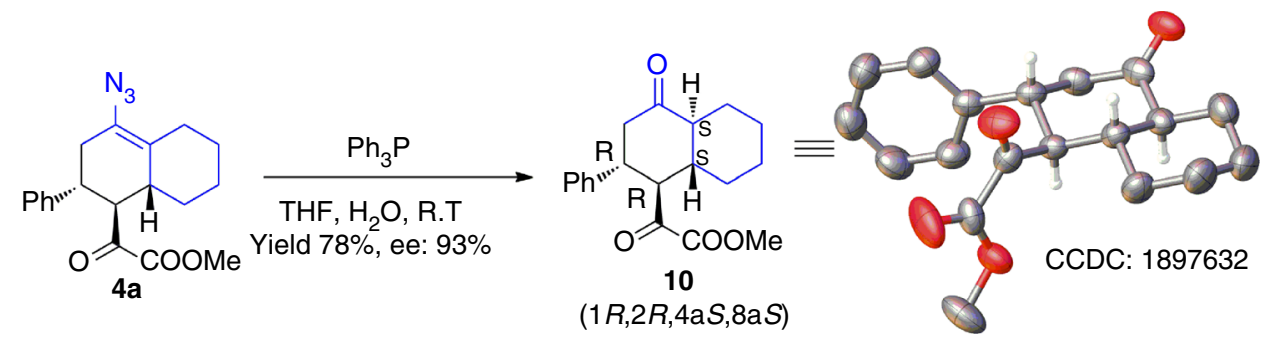

Fig. 2 Further synthetic applications of chiral cyclic azides and absolute configuration determination. a Click reaction of chiral cyclic azide $\mathbf{3 a}$ and the crystal structure of triazole 5. b Transformations of $\mathbf{3 a}$ into $\mathbf{6}, \mathbf{7}$, and $\mathbf{8}$. c Click reaction of chiral bicyclic azide $\mathbf{4 a}$. $\mathbf{d}$ Reduction of $\mathbf{4 a}$ into trans-decalone (10)

13-23). However, aliphatic benzyl group-substitued unsaturated ketoesters were not suitable substrates in this reaction, and no cycloaddition products were produced under standard conditions.

Asymmetric DA reaction to chiral decalin motif. To study the effect of conjugation in vinyl azides for the HDA reaction, we synthesized the $\alpha, \beta$-unsaturated azide (2m) and exposed it to the standard conditions. Very interestingly, a distinct product (4a), was formed as the sole product, albeit with low (21\%) ee through the $[2+4]$ Diels-Alder (DA) cycloaddition (Table 3, entry 1). An inverse-electron-demand HDA between $\mathbf{1 a}$ and $\mathbf{2} \mathbf{m}$, followed by a $[3,3]$-rearrangement could also produce the target product $4 a$. If this is the case, the first HDA reaction generally will give high enantioselectivities and since the second step is a stereospecific percyclic reaction, the product should be produced with good enantioselectivity. The low enantioselectivity obtained under previous standard conditions indicates that this might not be a hetero-Diels-Alder/[3,3]-rearrangement but a direct Diels-Alder reaction process. The reactivity of the vinylic $\pi$ bond might encourage it to act as a $4-\pi$ partner in a Diels-Alder reaction rather than the previous $2-\pi$ partner in the HDA reaction pathway.

We next aimed to get higher enantioselectivities in the synthesis of decalins and the obtained results are summarized in Table 3. $t$-Bu-BOX ligand with two sidearm $t$ - $\mathrm{BuC}_{6} \mathrm{H}_{4} \mathrm{CH}_{2}$ groups (L8) enhanced the ee to $73 \%$ (Table 3, entry 2). $t$-Bu-BOX with gem dimethyl groups at the bridging carbon (L3) gave the desired product with $75 \%$ yield and $80 \%$ ee (entry 3 ). The ee was further improved to $87 \%$, while maintaining good yield (78\%), by lowering the temperature to $-20^{\circ} \mathrm{C}$ (entry 4). Finally, we employed $t$-Bu-BOX ligands with a variable bite angle (L10, L11, and L12) and found the optimum conditions with a cyclopentyl-substituted $t$-Bu-BOX (L12), which gave the azidodecalin (4a) in $80 \%$ yield with $93 \%$ ee (entry 7 ). 
Using the optimum conditions, the substrate scope of the Diels-Alder reaction with respect to unsaturated ketoesters was evaluated (Table 4 ). Variously substituted unsaturated ketoesters produced the corresponding octahydronaphthalenes $(\mathbf{4 b}-\mathbf{4 g})$ in good yields (61-81\%) and with good-to-excellent enantioselectivity (82-93\%). Notably, all these reactions gave very good diastereoselectivity and no HDA product was observed. A fivemembered conjugated azido diene $\mathbf{2 n}$ was also synthesized and subjected to the Diels-Alder reaction, with the unsaturated ketoester $1 \mathrm{a}$ at $-30{ }^{\circ} \mathrm{C}$; the desired hexahydro-indene azide $\mathbf{4 h}$ was obtained with $87 \%$ yields, with $88 \%$ ee as a single diastereomer.

Synthetic applications and absolute configuration determination. To demonstrate the synthetic utility of the developed method, 3a was synthesized on a gram scale and several transformations were carried out. As shown in Fig. 2, a click reaction on 3a, produced the triazole (5) with $74 \%$ yield in good enatioselectivity (96\% ee). X-ray diffraction of a single crystal of this compound confirmed its structure, and the absolute configuration of compound $3 \mathbf{a}$ was established as $(2 S, 4 R)$. In the presence of a Lewis acid $\left(\mathrm{BF}_{3} \cdot \mathrm{Et}_{2} \mathrm{O}\right)$, 3a afforded chromene 6 in $64 \%$ yield, by the expulsion of hydrazoic acid. Treatment of $3 \mathbf{a}$ with $\mathrm{InCl}_{3}$ afforded a ring-opening product, a 1,5-diketone (7) in $85 \%$ yield. Likewise, a linear hydroxylfunctionalized tricarbonyl compound (8) was synthesized in 59\% yield, using $\mathrm{N}$-bromosuccinimide (NBS) and $\mathrm{H}_{2} \mathrm{O}$.

Further, synthetic transformations of the azido octahydro naphthalene (4a) were also performed. The triazole 9 was easily obtained in good yields and with retained enantioselectivities under traditional click conditions. Finally, under Staudinger reaction conditions, the decalin (4a) produced the trans-decalone (10), a ubiquitous structural unit in various natural products, in $78 \%$ yield with $93 \%$ ee. The absolute configuration of trans-decalone (10) was established as $(1 R, 2 R, 4 a S, 8 a S)$ by X-ray crystallography (Fig. 2).

\section{Discussion}

In summary, we have examined the reactivity of vinyl azides in asymmetric cycloaddition reactions for the synthesis of diverse chiral cyclic azides. $\alpha$-Aryl-substituted vinyl azides react with unsaturated ketoesters through inverse-electron-demand heteroDiels-Alder reaction, but cyclohexenyl azide reacts through diastereoselective and enantioselective Diels-Alder reactions. The prominent features of these reactions include 100\% atom economy, ambient reaction conditions, a very broad substrate scope, excellent enantioselectivities, and useful product applications. Further application of this strategy is in progress in our laboratory.

\section{Methods \\ Materials. All the solvents were treated according to standard methods. Unless otherwise noted, materials were purchased from commercial suppliers and used directly without further purification. Flash-column chromatography was per- formed using 100-200-mesh silica gel. All air-sensitive and moisture-sensitive reactions were performed under an atmosphere of $\mathrm{N}_{2}$ with standard Schlenk techniques. For ${ }^{1} \mathrm{H},{ }^{13} \mathrm{C}$ NMR and high-resolution mass spectrometry of com- pounds, the synthetic procedures, and details of the mechanism study, see Sup- plementary Methods.}

\section{Data availability}

The X-ray crystallographic structures for compounds $\mathbf{5 , 1 0}$, reported in this article, have been deposited at the Cambridge Crystallographic Data Centre (CCDC), with the accession codes CCDC 1891939 and 1897632 (http://www.ccdc.cam.ac.uk/data_request/cif). The authors declare that all other relevant data supporting the findings of this study are available within the article and its Supplementary Information files.

Received: 22 March 2019 Accepted: 25 June 2019

Published online: 18 July 2019

\section{References}

1. Bräse, S., Gil, C., Knepper, K. \& Zimmermann, V. Organic azides: an exploding diversity of a unique class of compounds. Angew. Chem. Int. Ed. 44, 5188-5240 (2005).

2. Fu, J., Zanoni, G., Anderson, E. A. \& Bi, X. a-Substituted vinyl azides: an emerging functionalized alkene. Chem. Soc. Rev. 46, 7208-7228 (2017).

3. Lin, T.-S. \& Prusoff, W. H. Synthesis and biological activity of several amino analogues of thymidine. J. Med. Chem. 21, 109-112 (1978).

4. Edagwa, B., Wang, Y. \& Narayanasamy, P. Synthesis of azide derivative and discovery of glyoxalase pathway inhibitor against pathogenic bacteria. Bioorg. Med. Chem. Lett. 23, 6138-6140 (2013).

5. Frost, J. R. et al. Callipeltosides A, B and C: total syntheses and structural confirmation. Chem. Eur. J. 21, 13261-13277 (2015).

6. Patel, J., Clavé, G., Renard, P.-Y. \& Franck, X. Straightforward access to protected syn $\alpha$-amino- $\beta$-hydroxy acid derivatives. Angew. Chem. Int. Ed. 47, 4224-4227 (2008).

7. Jewett, C. \& Bertozzi, C. R. Cu-free click cycloaddition reactions in chemical biology. Chem. Soc. Rev. 39, 1272-1279 (2010).

8. Agalave, S. G., Maujan, S. R. \& Pore, V. S. Click chemistry: 1,2,3-triazoles as pharmacophores. Chem. Asian J. 6, 2696-2718 (2011).

9. Xi, W., Scott, T. F., Kloxin, C. J. \& Bowman, C. N. Click chemistry in materials science. Adv. Funct. Mater. 24, 2572-2590 (2014).

10. Kolb, H. C., Finn, M. G. \& Sharpless, K. B. Click chemistry: diverse chemical function from a few good reactions. Angew. Chem. Int. Ed. 40, 2004-2021 (2001).

11. Shibatomi, K., Soga, Y., Narayama, A., Fujisawa, I. \& Iwasa, S. Highly enantioselective chlorination of $\beta$-keto esters and subsequent $S_{N} 2$ displacement of tertiary chlorides: a flexible method for the construction of quaternary stereogenic centers. J. Am. Chem. Soc. 134, 9836-9839 (2012).

12. Bosmani, A. et al. Stereoselective and enantiospecific mono and bis $\mathrm{C}-\mathrm{H}$ azidation of Tröger Bases: insight on bridgehead iminium intermediates and application to anion-binding catalysis. Chem. Eur. J. 23, 8678-8684 (2017).

13. Fernández-Valparis, J., Romea, P., Urpí, F. \& Font-Bardia, M. Stereoselective and catalytic synthesis of anti- $\beta$-alkoxy- $\alpha$-azido carboxylic derivatives. Org. Lett. 19, 6400-6403 (2017).

14. Ding, P.-G., Hu, X.-S., Zhou, F. \& Zhou, J. Catalytic enantioselective synthesis of a-chiral azides. Org. Chem. Front. 5, 1542-1559 (2018).

15. Martínez, L. E., Leighton, J. L., Carsten, D. H. \& Jacobsen, E. N. Highly enantioselective ring opening of epoxides eatalyzed by (salen) $\mathrm{Cr}$ (III) complexes. J. Am. Chem. Soc. 117, 5897-5898 (1995).

16. Fukuta, Y., Mita, T., Fukuda, N., Kanai, M. \& Shibasaki, M. De novo synthesis of Tamiflu via a catalytic asymmetric ring-opening of meso-aziridines with $\mathrm{TMSN}_{3}$. J. Am. Chem. Soc. 128, 6312-6313 (2006).

17. Wu, B., Parquette, J. R. \& RajanBabu, T. V. Regiodivergent ring opening of chiral aziridines. Science 326, 1662-1662 (2009).

18. Taylor, M. S., Zalatan, D. N., Lerchner, A. M. \& Jacobsen, E. N. Highly enantioselective conjugate additions to $\alpha, \beta$-unsaturated ketones catalyzed by a (Salen)Al complex. J. Am. Chem. Soc. 127, 1313-1317 (2005).

19. Guerin, D. J. \& Miller, S. J. Asymmetric azidation-cycloaddition with openchain peptide-based catalysts. A sequential enantioselective route to triazoles. J. Am. Chem. Soc. 124, 2134-2136 (2002).

20. Khrakovsky, D. A. et al. Enantioselective, stereodivergent hydroazidation and hydroamination of allenes catalyzed by acyclic diaminocarbene (ADC) gold(I) complexes. Angew. Chem. Int. Ed. 55, 6079-6083 (2016).

21. Zhou, P.-F. et al. Iron-catalyzed asymmetric haloazidation of $\alpha, \beta$-unsaturated ketones: construction of organic azides with two vicinal stereocenters. J. Am. Chem. Soc. 139, 13414-13419 (2017).

22. Deng, Q.-H., Bleith, T., Wadepohl, H. \& Gade, L. H. Enantioselective ironcatalyzed azidation of $\beta$-keto esters and oxindoles. J. Am. Chem. Soc. 135, 5356-5359 (2013)

23. Huang, X.-Y., Bergsten, T. M. \& Groves, J. T. Manganese-catalyzed late-stage aliphatic C-H azidation. J. Am. Chem. Soc. 137, 5300-5303 (2015).

24. Ott, A. A., Goshey, C. S. \& Topczewski, J. Dynamic kinetic resolution of allylic azides via asymmetric dihydroxylation. J. Am. Chem. Soc. 139, 7737-7740 (2017).

25. McNulty, J. \& Zepeda-Velázquez, C. Enantioselective organocatalytic Michael/ Aldol sequence: anticancer natural product $(+)$-trans-dihydrolycoricidine. Angew. Chem. Int. Ed. 53, 8450-8454 (2014).

26. $\mathrm{Gu}, \mathrm{P}$. et al. Enantioselective preparation of cis- $\beta$-azidocyclopropane esters by cyclopropanation of azido alkenes using a chiral dirhodium catalyst. Org. Lett. 14, 2246-2249 (2012).

27. Weidner, K., Sun, Z.-D., Kumagai, N. \& Shibasaki, M. Direct catalytic asymmetric aldol reaction of an a-azido amide. Angew. Chem. Int. Ed. 54, 6236-6240 (2015).

28. Noda, H., Amemiya, F., Weidner, K., Kumagai, N. \& Shibasaki, M. Catalytic asymmetric synthesis of $\mathrm{CF}_{3}$-substituted tertiary propargylic alcohols via direct aldol reaction of $\alpha-\mathrm{N}_{3}$ amide. Chem. Sci. 8, 3260-3269 (2017). 
29. Liu, Z., Liao, P. \& Bi, X. General silver catalyzed hydro azidation of terminal alkynes by combining TMS- $\mathrm{N}_{3}$ and $\mathrm{H}_{2} \mathrm{O}$ : synthesis of vinyl azides. Org. Lett. 16, 3668-3671 (2014).

30. Hayashi, H., Kaga, A. \& Chiba, S. Application of vinyl azides in chemical synthesis: a recent update. J. Org. Chem. 82, 11981-11989 (2017).

31. Hu, B. \& DiMagno, S. G. Reactivities of vinyl azides and their recent applications in nitrogen heterocycle synthesis. Org. Biomol. Chem. 13, 3844-3855 (2015).

32. Jung, N. \& Bräse, S. Vinyl and alkynyl azides: Well-known intermediates in the focus of modern synthetic methods. Angew. Chem. Int. Ed. 51, 12169-12171 (2012).

33. Wang, Y., Toh, K. K., Ng, E. P. J. \& Chiba, S. Mn(III)-mediated formal [3+3]annulation of vinyl azides and cyclopropanols: a divergent synthesis of azaheterocycles. J. Am. Chem. Soc. 133, 6411-6421 (2011).

34. Wang, Y., Toh, K. K., Lee, J. \& Chiba, S. Synthesis of isoquinolines from a-aryl vinyl azides and internal alkynes by $\mathrm{Rh}-\mathrm{Cu}$ bimetallic co-operation. Angew. Chem. Int. Ed. 50, 5927-5931 (2011).

35. Xuan, J. et al. Visible-light induced formal [3+2] cycloaddition for pyrrole synthesis under metal-free conditions. Angew. Chem. Int. Ed. 53, 5653-5656 (2014).

36. Farney, E. P. \& Yoon, T. P. Visible-light sensitization of vinyl azides by transition-metal photocatalysis. Angew. Chem. Int. Ed. 53, 793-797 (2014).

37. Ning, Y., Ji, Q., Liao, P., Anderson, E. A. \& Bi, X. Silver-catalyzed stereoselective aminosulfonylation of alkynes. Angew. Chem. Int. Ed. 56, 13805-13808 (2017).

38. Ning, Y., Zhao, X., Wu, Y. \& Bi, X. Radical enamination of vinyl azides: direct synthesis of N-unprotected enamines. Org. Lett. 19, 6240-6243 (2017).

39. Kanchupalli, V. \& Katukojvala, S. $[1+1+3]$ annulation of diazoenals and vinyl azides: direct synthesis of functionalized 1-pyrrolines through olefination. Angew. Chem. Int. Ed. 57, 5433-5535 (2018).

40. Huang, X. et al. Catalytic asymmetric synthesis of a nitrogen heterocycle through stereocontrolled direct photoreaction from electronically excited state. Nat. Commun. 8, 2245-2253 (2017).

41. Zhang, F., Wang, Y., Lonca, G. H., Zhu, X. \& Chiba, S. Amide synthesis by nucleophilic attack of vinyl azides. Angew. Chem. Int. Ed. 53, 4390-4394 (2014).

42. Thirupathi, N., Tung, C.-H. \& Xu, Z. Scandium (III)-catalyzed cycloaddition of in situ generated ortho-quinone methides with vinyl azides: an efficient access to substituted 4H-chromenes. Adv. Synth. Catal. 360, 3585-3589 (2018).

43. López, E. \& López, L. A. Synthesis of functionalized cyclopentene derivatives from vinyldiazo compounds and vinylazides through sequential copperpromoted [3+2] cycloaddition/azide rearrangement. Angew. Chem. Int. Ed. 56, 5121-5124 (2017).

44. Nay, B., Riache, N. \& Evanno, L. Chemistry and biology of non-tetramic $\gamma$ hydroxy- $\gamma$-lactams and $\gamma$-alkylidene- $\gamma$-lactams from natural sources. Nat. Prod. Rep. 26, 1044-1062 (2009).

45. Li, G., Kusari, S. \& Spiteller, M. Natural products containing 'decalin' motif in microorganisms. Nat. Prod. Rep. 31, 1175-1201 (2014)

46. Hung, K., Hu, X. \& Maimone, T. J. Total synthesis of complex terpenoids employing radical cascade processes. Nat. Prod. Rep. 35, 174-202 (2018).

47. Macros, I. S. et al. Synthesis and biological activity of polyalthenol and pentacyclindole analogues. Eur. J. Med. Chem. 73, 265-279 (2014).

48. Hwang, I. H. et al. Cytotoxic activity of rearranged drimane meroterpenoids against colon cancer cells via down-regulation of $\beta$-Catenin expression. J. Nat. Prod. 78, 453-461 (2015).

49. Li, G. et al. Epigenetic modulation of endophytic eupenicillium sp. LG41 by a histone deacetylase inhibitor for production of decalin-containing compounds. J. Nat. Prod. 80, 983-988 (2017).

50. Larson, R. T., Pemberton, R. P., Franke, J. M., Tantillo, D. J. \& Thompson, R. J. Total synthesis of the Galbulimima alkaloids Himandravine and GB17 using biomimetic Diels-Alder reactions of double diene precursors. J. Am. Chem. Soc. 137, 11197-11204 (2015).

51. Liao, S., Sun, X. L. \& Tang, Y. Side arm strategy for catalyst design: modifying bisoxazolines for remote control of enantioselection and related. Acc. Chem. Res. 47, 2260-2272 (2014).

52. Liu, Q. et al. Highly enantioselective $[3+2]$ annulation of indoles with quinones to access structurally diverse benzofuroindolines. Angew. Chem. Int. Ed. 57, 3810-3876 (2018).

53. Feng, L.-W. et al. Reaction of donor-acceptor cyclobutanes with Indoles: general protocol for the formal total synthesis of $( \pm)$-strychnine and the total synthesis of $( \pm)$-Akuammicine. Angew. Chem. Int. Ed. 56, 3055 (2017).

54. Wang, L., Zhou, J. \& Tang, Y. Sidearm modified bisoxazoline ligands and their applications. Chin. J. Chem. 36, 1123-1129 (2018).

55. Zhou, J. \& Tang, Y. Sidearm effect: improvement of the enantiomeric excess in the asymmetric michael addition of Indoles to alkylidene malonates. J. Am. Chem. Soc. 124, 9030-9031 (2002).

\section{Acknowledgements}

We are grateful for financial support from the Natural Science Foundation of China (no. 21572118), and Tang scholar award and The Fundamental Research Funds of Shandong University.

\section{Author contributions}

N.T. and F.W. have successfully done most of the experiments. Z.X. conceptualized and directed the project, and drafted the paper with the assistance from all the coauthors. C.H.T. revised the paper. All authors discussed the results and commented on the paper.

\section{Additional information}

Supplementary Information accompanies this paper at https://doi.org/10.1038/s41467 019-11134-8.

Competing interests: The authors declare no competing interests.

Reprints and permission information is available online at http://npg.nature.com/ reprintsandpermissions/

Peer review information: Nature Communications thanks Xihe Bi and other anonymous reviewer(s) for their contribution to the peer review of this work

Publisher's note: Springer Nature remains neutral with regard to jurisdictional claims in published maps and institutional affiliations.

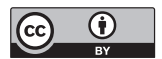

Open Access This article is licensed under a Creative Commons Attribution 4.0 International License, which permits use, sharing, adaptation, distribution and reproduction in any medium or format, as long as you give appropriate credit to the original author(s) and the source, provide a link to the Creative Commons license, and indicate if changes were made. The images or other third party material in this article are included in the article's Creative Commons license, unless indicated otherwise in a credit line to the material. If material is not included in the article's Creative Commons license and your intended use is not permitted by statutory regulation or exceeds the permitted use, you will need to obtain permission directly from the copyright holder. To view a copy of this license, visit http://creativecommons.org/ licenses/by/4.0/.

(c) The Author(s) 2019 